\title{
A cooperação internacional e a pandemia de COVID-19 na perspectiva da proteção do "whistleblower"
}

\author{
Recebido: 31 de agosto de 2020 - Aprovado: 5 de novembro de 2020 \\ https://doi.org/10.22395/ojum.v20n42a19
}

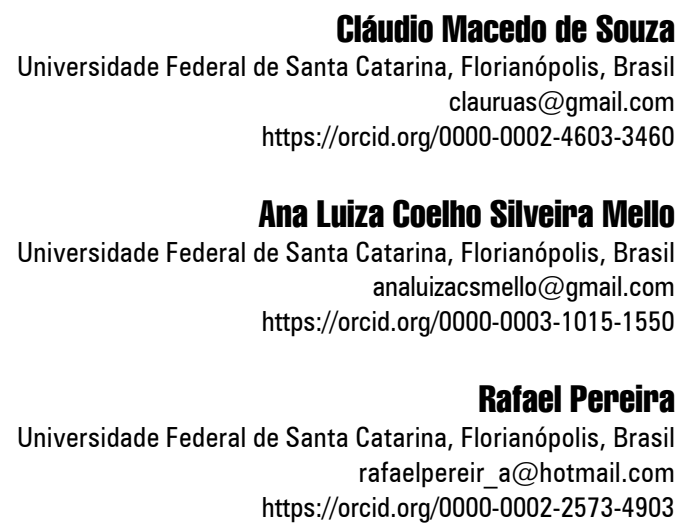

\section{RESUMO}

Este artigo propõe a aplicação do instituto do whistleblowing ao caso do médico chinês "Li Wenliang" por considerá-lo whistleblower, devido aos alertas emitidos em relação à pandemia de COVID-19. Em decorrência da ausência de proteção e do silêncio que lhe fora imposto, indagou-se: "Quais condições jurídicas expressam o direito de proteção do médico que relatou voluntariamente riscos específicos de saúde pública?" Infere-se que o direito à proteção do denunciante de boa-fé respaldado pelo instituto do whistleblowing, legitimado pelos direitos humanos, e garantido pela cooperação internacional expressam as condições jurídicas necessárias para a solução do caso do médico chinês. A metodologia utilizada consistiu no método dedutivo para a partir do instituto do whistleblowing avaliar o caso do médico chinês. O direito de ter sido protegido pelas autoridades chinesas estava legitimado pelos direitos humanos e respaldado legalmente pelo whistleblowing porque era um denunciante de riscos específicos para a saúde pública. O médico era detentor de personalidade internacional, sendo, portanto, consagrado como sujeito de direito perante as instituições internacionais, sendo legítima a exigência dos direitos humanos como forma de impedir eventuais retaliações. Conclui-se que o direito à proteção é, portanto, compromisso de aspiração moral cuja validade jurídica e política dependem da cooperação internacional.

Palauras-chave: whistleblowing; whistleblower; cooperação internacional; pandemia de COVID-19; direitos Humanos. 


\section{International Cooperation and the COVID-19 Pandemic in the Perspective of the "Whistleblower" Protection}

\section{ABSTRACT}

This article proposes the application of the whistleblowing institute in the case of the Chinese medic Li Wenliang by considering him a whistleblower due to the alerts he emitted about the COVID 19 pandemic. In face of the absence of protection and the silence imposed on him the following was asked: Which judicial conditions express the right for protection to the the medic that voluntarily exposed the specific risks for public health? The article concludes that the right for protection for the informer in good faith is backed by the whistleblower figure, corroborated by Human Rights and guaranteed by international cooperation, thus expressing the necessary judicial conditions for solving the Chinese medic case. The methodology employed was based on the deductive approach; starting from the whistleblowing institute the case of the Chinese medic is then assessed. The right for protection by the Chinese authorities was legitimized by Human Rights and legally by the whistleblowing figure, for being an informer on specific risks for public health. The medic was a holder of international personality, being, thus, a subject of law in front of the international institutions eyes and being legitimate the demand for Human Rights as a way for impeding future retaliations. It is concluded that the right for protections is a compromise of moral aspiration which judicial and political validity depend on international cooperation.

Keywords: Whistleblowing; Whistleblower; International Cooperation; COVID-19 pandemic; Human Rights.

\section{La cooperación internacional y la pandemia del COVID-19 en la perspectiva de protección del "whistleblower"}

\section{RESUMEN}

El presente artículo propone la aplicación del instituto del whistleblowing en el caso del médico chino "Li Wenliang" por considerarlo whistleblower, debido a los alertas emitidos frente a la pandemia de la COVID-19. Ante la ausencia de protección y del silencio impuesto, se preguntó: ¿Qué condiciones jurídicas expresan el derecho de protección del médico que expuso voluntariamente los riesgos específicos de salud pública? Concluyese que el derecho a la protección del delator de buena fe respaldado por el instituto whistleblowing, corroborado por los derechos humanos, y garantizado por la cooperación internacional expresan las condiciones jurídicas necesarias para la solución del caso del médico chino. La metodología empleada se basó en el método deductivo, a partir del instituto whistleblowing, evaluar el caso de médico chino. El derecho de haber sido protegido por las autoridades chinas estaba legitimado por los derechos humanos y respaldados legalmente por whistleblowing, por ser un denunciante de riesgos específicos para la salud pública. El médico era detentor personalidad internacional, siendo, por lo tanto, consagrado como sujeto de derecho ante las instituciones internacionales, siendo legítima la exigencia de los derechos humanos como forma de impedir eventuales retaliaciones. Se concluye que el derecho a la protección es, compromiso de aspiración moral cuya validad jurídica y política dependen de cooperación internacional. Palabras clave: Whistleblowing; Whistleblower; Cooperación internacional; Pandemia de la Covid-19; Derechos Humanos. 


\section{INTRODUÇÃOO}

Este estudo deriva-se da atuação de pesquisa dos autores como pesquisadores na área do Direito Penal, Direito Penal Internacional e Cooperação Internacional em Matéria Penal. O artigo propõe a aplicação do instituto do whistleblowing ao caso do médico chinês "Li Wenliang" por considerá-lo merecedor de proteção pela via da cooperação internacional devido à sua condição de whistleblower ou de denunciante de boa-fé. O caso em discussão envolve o alerta do médico emitido aos companheiros de trabalho sobre o surto da doença de Covid-19 e a recomendação para que usassem equipamentos de segurança a fim de evitarem a contaminação e a disseminação do vírus.

Por causa deste alerta, Li Wenliang foi forçado a assinar uma carta na qual prometia não divulgar informações sobre a doença. Apontado como um dos primeiros a identificar a existência do surto do novo coronavirus e alertar colegas, Li Wenliang foi investigado pela polícia chinesa sob acusação de "espalhar boatos" relacionados à doença. O médico, ao tentar alertar voluntariamente um grupo de colegas a usarem medidas de proteção contra esta doença infecciosa, não recebeu proteção das autoridades de seu país. Pelo contrário, foi silenciado e veio a óbito no início de 2020, devido à doença causada pelo vírus SARS-CoV-2.

Disto resulta que a origem do problema gravitou em torno da ausência de proteção ao médico em decorrência do silêncio que lhe fora imposto pelas autoridades. Respaldado e atento a esta situação, indaga-se: "Quais condições jurídicas expressam o direito de proteção do médico que relatou voluntariamente riscos específicos de saúde pública?" Supõe-se que o direito à proteção do denunciante de boa-fé respaldado pelo instituto do whistleblowing, legitimado pelos direitos humanos e garantido pela cooperação internacional, expressam as condições jurídicas necessárias para a solução do caso do médico chinês.

Previsto na legislação de diversos países, o instituto possibilita a atuação por parte dos Estados e de organismos internacionais para apuração de irregularidades e de ilícitos denunciados às autoridades competentes. Embora possam existir irregularidades relacionadas aos atos de corrupção, na Europa e nos EUA, o cidadão é protegido ao relatar fatos de interesse público, inclusive, aqueles que colocam em risco a saúde da coletividade.

Nesta direção, o artigo parte do pressuposto de que a proteção da pessoa humana é matéria comum à cooperação internacional e ao instituto do whistleblowing. Na verdade, trata-se de reconhecer que o instituto, contextualizado a partir do caso do médico chinês, conduz o artigo à busca de uma resposta global na qual cada Estado deve ser o depositário fiel da proteção da pessoa humana enquanto valor universal.

A resposta global implica em proteger pessoas que se colocam em uma situação de risco ao portarem informações valiosas, passíveis de gerarem a apuração pelas 
autoridades do fato relatado. Pois bem, a ideia de proteção do whistleblower por meio da cooperação internacional impõe o fortalecimento de uma consciência política de respeito a valores comuns da humanidade.

Dividido em duas etapas, o artigo se utiliza do método dedutivo para, a partir do instituto do whistleblowing, avaliar o caso do médico chinês e sua relação com a cooperação internacional. Na primeira etapa, o artigo afirma a condição de denunciante de boa-fé do médico chinês e aborda aspectos conceituais da sua proteção prevista no instituto do Whistleblowing. Destaca, ainda, sob a ótica da Carta das Nações Unidas e da Declaração Universal dos Direitos Humanos, a proteção da pessoa humana enquanto direito que o encoraja a prestar informações a respeito de fatos ilícitos dos quais possui conhecimento.

Na segunda etapa, o texto reafirma o seu status de sujeito merecedor de proteção; mas, também, reconhece a cooperação entre países como fórum importante de garantia do direito de ser protegido na esfera internacional. Propósito fundador da Carta das Nações Unidas, a cooperação surge como garantia da solução de problemas internacionais e do respeito aos direitos humanos. Ao final, constata-se que os países têm o dever de cooperar na proteção da pessoa, tendo em vista que os direitos humanos devem reger as relações internacionais.

\section{DA SALVAGUARDA DO DIREITO DO DENUNCIANTE DE BOA-FÉ}

No contexto da pandemia, é fundamental salvaguardar o direito de quem denuncia a verdade sobre a propagação da doença, para as populações dos países afetados poderem responder de maneira adequada e eficaz. Neste aspecto, o denunciante ou whistleblower pode desempenhar papel vital de alerta inicial, porque funciona como mecanismo de segurança automático, especialmente durante uma crise de saúde internacional.

A palavra whistleblower, como a própria tradução livre quer dizer - "whistle" "apito" e "Glower" "soprador" é a pessoa que "sopra o apito" (Oliveira, 2015). O termo "soprar o apito" surge de uma analogia que consistia na típica situação em que as autoridades policiais britânicas, para alertarem sobre o cometimento de irregularidades, "assopravam o apito" ao perceberem que um crime estava sendo cometido (Triviño, 2018).

Em meados dos anos 70 do século XX, o termo ganhou força nos Estados Unidos da América, que passou a utilizá-lo no âmbito privado, principalmente, nas grandes empresas a fim de que fossem detectadas e combatidas irregularidades e os desvios de condutas, inclusive as corruptelas (Mota Jr, 2012).

Apesar de inexistir uma conceituação jurídica comum para whistleblowing, é consenso que consiste em boa-fé a atitude de um sujeito que leva às autoridades competentes informações as quais acredita ser evidências de crime, conduta ímproba, violações de 
obrigações legais, "(...) riscos específicos para a saúde pública, segurança ou meio ambiente, abuso de autoridade, uso não autorizado de fundos ou bens públicos, má gestão, conflitos de interesses e atos para encobrir qualquer uma das práticas mencionadas" (Ramos, 2018, p. 6-7), assim como assuntos de relevante interesse público.

Segundo a Transparência Internacional, o ato de praticar a denúncia ou whistleblowing não precisa necessariamente ser feito por uma pessoa que trabalhe no setor público. Ao contrário, pode ser feito por qualquer pessoa, inclusive do setor privado, que por algum motivo teve conhecimento de indícios de irregularidades ou ilegalidades ocorridas ou que estão em vias para o cometimento (Ramos, 2018).

Todavia, é importante a boa-fé do cidadão no momento de prestar a denúncia, bem como o conhecimento sobre o assunto a ser denunciado. Isso não significa que as informações por ele prestadas sejam verdadeiras, mas é necessário que haja indícios de ilegalidade ou irregularidade, evitando-se denúncias vazias (Mota Jr, 2012).

Outro ponto merecedor de atenção é acerca das diferenças existentes entre as figuras do delator e do denunciante - whistleblower. O delator é considerado aquele que comete um ato ilícito de natureza penal, ou então dele participa de alguma maneira, ainda que como partícipe, e, posteriormente, decide colaborar com a Justiça em troca de benefícios em sua condenação. Nessa situação, tem-se a chamada colaboração premiada, que, no âmbito das pessoas jurídicas, recebe o nome de acordo de leniência.

Já o whistleblower refere-se ao sujeito que não teve participação no ilícito. Essa pessoa pode ser um funcionário público, um empregado de uma empresa privada, um consumidor ou um terceiro qualquer, que por algum motivo, possui informações acerca de possíveis ilícitos. A presente figura se distingue da primeira, pois o sujeito, ao tomar conhecimento acerca de irregularidades ou ilícitos, leva ao conhecimento da autoridade competente a fim de que sejam adotadas as providências cabíveis à espécie (Enccla, 2016).

O denunciante não é processado como acontece com o delator e figurará no processo como mera testemunha, podendo, inclusive, a depender do caso, receber incentivo monetário pelas informações que prestar às autoridades competentes. Já o delator em colaboração premiada poderá ter benefícios na própria pena e figurará no processo como réu (Rosa, 2018).

Superada esta diferenciação, destacam-se dois casos paradigmáticos de denunciantes de repercussão internacional: o Edward Snowden ocorrido nos Estados Unidos da América (Greenwald, MacAskill e Poitras, 2013) e de Julian Assange responsável pelo Wikileaks (Miguel, 2019). Em ambos, os denunciantes trouxeram ao público irregularidades e crimes, mesmo sabendo antecipadamente dos possíveis efeitos colaterais em 
suas vidas, tanto no âmbito profissional como no pessoal, pelas possíveis ameaças e retaliações (Ramos, 2018).

Incorporado em diversos ordenamentos jurídicos, dentre eles, Reino Unido, Estados Unidos da América, França, Alemanha e Portugal (Oliveira, 2015), o instituto do denunciante, utilizou como ponto referencial para a edição das legislações as recomendações da organização não governamental da Transparência Internacional, que inseriu em seus diversos relatórios os seguintes princípios:

b) a criação de sistemas e órgãos internos de delação (incentivise internal reporting e whistleblower complains authority);

c) mecanismos ou incentivos para estimular a delação (rewards systems);

d) proteção da identidade do delator (protection of identity);

e) inversão do ônus da prova na comprovação da delação (reversed burden of proof);

f) imunidade civil, penal e administrativa para o delator de boa-fé (waiver of liability);

g) punição àquele que fizer retaliação ao delator (penalty for retaliation and interference);

h) ausência de sanções na hipótese de denúncias equivocadas, se fundadas em erro honesto (no sanctions for misguided reporting); bem como

i) a invalidação de regras particulares que obstruam os efeitos da legislação denunciante (no circumvention) (MPPR, [s.d.).).

O direito à proteção do denunciante, é princípio legitimado pelos direitos humanos, norteador das legislações pertinentes ao tema e responsável pela segurança do denunciante, encoraja a pessoa para que preste informação das quais tenha conhecimento. Assegura-lhe, que nenhuma espécie de retaliação ou punição lhe ocorra, como por exemplo, a criação de uma barreira ao assédio moral.

O encorajamento do denunciante em prestar informações de forma segura e apropriada está relacionado, inclusive, com a garantia do sigilo de seus dados. O anonimato promove o fomento à prática de denunciar, o que torna o instituto eficiente e eficaz. Ademais, para evitar retaliação, existe também a possibilidade de criação de políticas internas de proteção a fim de garantir uma espécie de estabilidade por um determinado período ao empregado denunciante (Ramos, 2018).

No entanto, as políticas de proteção existentes, não raras vezes, aparecem de forma lacônica, sem especificar e detalhar, objetivamente, como a proteção ocorrerá no caso prático, quando da realização da denúncia pelo whistleblower. Portanto, definir a forma de proteção é de extrema importância, pois ao se expor, o denunciante sai da sua zona de conforto e, assim, coloca em risco não apenas a sua integridade física e psíquica, mas também a vida da sua família e a sua própria. 
Em alguns países, como nos EUA, verificou-se que diversas pessoas com informações suficientes para se tornarem denunciantes, não ocupariam tal papel por livre e espontânea vontade. Afinal de contas, estariam se expondo e se arriscando por um mero dever cívico. Por essa razão, foi idealizada a criação de mecanismos de incentivo para estimular pessoas a denunciar (Paiva e Pegoraro, 2018).

Embora seja tema ainda controverso, o mecanismo de incentivo baseado na recompensa monetária é outro aspecto discutido e aceito em diversos países como estratégia para tornar os canais de denúncias mais atrativos, tanto para os denunciantes quanto para o ente público e privado que precisa investigar ilícitos ou possíveis ilícitos (Maslen, 2018).

Na Europa existe uma aversão moral (que se traduz numa inexistência normativa) a estas soluções, mas nos EUA existe um sistema de recompensas no qual é permitido a um cidadão, em nome do Estado, processar alguém que tenha defraudado o Estado para recuperar esse dinheiro, podendo o cidadão receber até $30 \%$ da quantia recuperada. Ou ainda, a Comissão do Mercado de Valores Mobiliários dos EUA pode conferir denunciantes de violações à lei financeira recompensas de entre 10 a 30\% dos valores recuperados (Ramos, 2018, p. 38).

Outra crítica às premiações considera que uma ínfima parte dos whistleblowers de fato receberia quantias monetárias, visto que a recompensa somente é paga nos casos cujas informações prestadas consigam efetivamente conduzir a uma investigação e, sobretudo, à recuperação de valores. Ademais, outro possível problema gerado pelas premiações relaciona-se às infundadas denúncias que poderiam inclusive causar danos a sujeitos inocentes (Paiva e Pegoraro, 2018).

Embora pouco se saiba sobre a sua aplicabilidade, no Brasil, o whistleblower surge com o advento da Lei 13.608, de 10 de janeiro de 2018 e com as alterações promovidas pela Lei 13.964/2019, com destaque para a figura do "informante" ao invés de denunciante (Paiva e Pegoraro, 2018).

Após as alterações legais, o texto passou a dispor especificamente sobre o serviço telefônico de recebimento de denúncias - "disque denúncia". Com isso, os Estados Federados e o Distrito Federal estão autorizados a estabelecerem centrais para o recebimento de denúncias por telefone, assegurando ao denunciante o "sigilo dos seus dados". Ademais, previu compensação pecuniária como recompensa pelas informações úteis que prestar à Administração Pública (Beltrame e Sahione, 2019).

Apresentadas pelos whistleblowers, as denúncias devem contemplar informações concretas acerca dos fatos e da autoria dos ilícitos, objeto da denúncia. Não é suficiente para a deflagração da investigação ou instauração de inquérito policial a mera desconfiança do ilícito. As informações prestadas devem ser no mínimo concretas para que se dê providência às investigações pela autoridade pública competente, conforme entendimento do Superior Tribunal de Justiça brasileiro (STJ, 2017). 
No âmbito de proteção da pessoa, asseguram-se aos denunciantes a sua não retaliação, o seu anonimato e, ainda, uma compensação monetária a título de recompensa que poderá ser-lhe paga no percentual de até $5 \%$ do valor restituído à Administração Pública, quando da apuração do fato resultar em recuperação de ativos aos cofres públicos. ${ }^{1}$

Destaca-se que o direito à proteção do whistleblower além de possibilitar às autoridades competentes o conhecimento prévio de possíveis ilícitos, permite a realização de investigações para a apuração de potenciais crimes contra o interesse público, contribuindo para uma cultura transparente e responsável, (Beltrame E Sahione, 2019).

Ademais, a proteção da pessoa é um marco na história das Nações Unidas fundada na paz e na segurança internacional. A cooperação entre Estados representa esta segurança internacional. Portanto, a Carta da ONU já previa que a solução para os mais diversos desafios da atualidade seria por meio da cooperação internacional.

\section{COOPERAÇÃO INTERNACIONAL: GARANTIA DE PROTEÇÃO DO WHISTLEBLOWER}

A proteção da pessoa e, particularmente do médico chinês, está respaldada em diversos documentos internacionais de direitos humanos, incluindo a Carta das Nações Unidas (1945), a Declaração Universal dos Direitos Humanos (1948), a Carta da Organização dos Estados Americanos (1948), a Declaração Americana dos Direitos e Deveres do Homem (1948) e a Convenção Americana sobre Direitos Humanos (1969). A cooperação internacional, prevista nos referidos documentos, emerge como garantia para assegurar a plena efetividade dos direitos da pessoa humana.

Neste aspecto, a cooperação internacional está ligada na sua essência à garantia dos direitos humanos. Portanto, o problema que envolve a proteção do médico chinês não se afasta desse debate; pelo contrário, exige dele uma solução, marcada pela cooperação internacional.

Diante do surto de COVID-19, o médico Dr. Li Wenliang agiu como um whistleblower ao relatar e alertar, em dezembro de 2019, um grupo de médicos e de ex-alunos que o departamento de oftalmologia do hospital havia diagnosticado sete pacientes com sintomas semelhantes a uma síndrome respiratória aguda grave (SARS) e que essas pessoas tinham ligação com um mercado local de frutos do mar (Nikkei Asian Review, 2020) (Petersen et al, 2020).

No início de janeiro de 2020, a polícia local ao tomar conhecimento deste fato, convocou o médico, que nesta ocasião foi detido e advertido por estar "fazendo comentários falsos na Internet". Obrigando-o e forçando-o a assinar um documento policial

No Brasil a Lei n. 13.608, de 10 de janeiro de 2018. Dispõe sobre o serviço telefônico de recebimento de denúncias e sobre recompensa por informações que auxiliem nas investigações policiais; e altera o art. 4o da Lei no 10.201, de 14 de fevereiro de 2001, para prover recursos do Fundo Nacional de Segurança Pública para esses fins. 
que admitia ter perturbado seriamente a ordem social, bem como ter violado a lei (The Guardian, 2020).

Ainda em janeiro de 2020, dr. Li Wenliang apresentou febre, sendo posteriormente diagnosticado com COVID-19, e, em 7 de fevereiro de 2020, faleceu na UTI (Unidade de Tratamento Intensivo) em decorrência de complicações da doença (CNN, 2020). Ao tentar alertar voluntariamente o público acerca da gravidade dos fatos não recebeu proteção das autoridades de seu país. Pelo contrário, foi humilhado, silenciado e faleceu devido à doença causada pelo vírus SARS-CoV-2 (Nie, Elliott, 2020).

No contexto do instituto do whistleblowing, a cooperação internacional pode ser entendida como um ato formal de solicitar a outro país alguma medida judicial, investigativa ou administrativa necessária para a proteção do denunciante de boa-fé a partir de um caso concreto. Esta proteção, dentro de um cenário de intensificação das relações entre as nações e seus povos, demanda cada vez mais um Estado colaborativo.

A proteção do denunciante de boa-fé não se processa mais dentro de um só Estado Soberano, pois é necessário cooperar e pedir a cooperação de outros Estados para serem satisfeitas as pretensões por justiça do indivíduo e da sociedade. Propósito da Carta da ONU, a cooperação busca a solução de problemas internacionais de caráter econômico, social, cultural ou humanitário e também o respeito pelos direitos humanos e pelas liberdades fundamentais para todos, sem distinção de raça, sexo, língua ou religião. ${ }^{2}$

A recorrente e contínua necessidade de cooperação internacional, nas mais diversas searas de aplicação do Direito, impulsiona a construção e o desenvolvimento de entes internacionais capazes de gerenciar interesses da sociedade internacional das mais variadas destinações (Mazzuoli, 2015).

A Declaração Universal dos Direitos Humanos, gerente dos interesses da sociedade internacional, estabelece a proteção universal ao afirmar que toda pessoa "como membro da sociedade, tem direito à segurança social e à realização, pelo esforço nacional, pela cooperação internacional e de acordo com a organização e recursos de cada Estado, dos direitos econômicos, sociais e culturais indispensáveis à sua dignidade e ao livre desenvolvimento de sua personalidade".3

Presente no instituto do whistleblowing, a concreta proteção do médico chinês pode ser extraída, por exemplo, da Convenção das Nações Unidas Contra a Corrupção.

2 O art. 13 da Carta da ONU previu que a Assembléia Geral iniciaria estudos e faria recomendações destinadas à promoção da cooperação internacional nos terrenos econômico, social, cultural, educacional e sanitário e favoreceria o pleno gozo dos direitos humanos e das liberdades fundamentais, por parte de todos os povos, sem distinção de raça, língua ou religião.

3 Compromisso previsto no artigo 22 da Declaração Universal dos Direitos Humanos. 
Este documento assegura a proteção aos denunciantes de boa-fét e representa o interesse da comunidade internacional de delinear um acordo verdadeiramente global para a proteção do denunciante.

A Carta da ONU confere ao médico chinês o status de sujeito merecedor de proteção, mas também lhe garante este direito ao reconhecer a cooperação internacional como fórum importante de debate e de resolução de problemas comuns à humanidade.

A partir deste raciocínio, observa-se que a cooperação internacional funciona como instrumento de garantia da dogmática dos direitos humanos e, por isso, o caso do médico chinês deveria ter recebido dos direitos fundamentais os mais fortes impulsos.

Os direitos humanos possuem uma dimensão interna, vinculada à ordem jurídica de cada país e, outra, externa, vinculada ao direito internacional e com pretensões de universalidade. E, para compreender o caso do médico chinês, interessa-nos desenvolver a dimensão externa (internacional) dos direitos humanos.

Para citar apenas um exemplo, o Preâmbulo da Convenção Americana sobre Direitos Humanos reconhece que direitos essenciais não derivam do fato do homem ser nacional de determinado Estado, mas sim do fato de ter como fundamento os atributos da pessoa humana, razão por que justificam sua proteção internacional.

Neste caso, a proteção internacional do médico chinês era indispensável, tendo em vista que um conjunto de casos severos provenientes de uma doença respiratória cuja causa era desconhecida havia sido registrado em Wuhan, província de Hubei. Um novo vírus, pertencente à família do Coronavirus, o SARS-CoV-2, foi identificado como o causador desta doença então nominada de COVID-19 (Zhou et al, 2020).

Em 30 de janeiro de 2020, a Organização Mundial da Saúde declarou o surto COVID-19 uma Emergência de Saúde pública de Importância Internacional (ESPII), o que correspondeu ao maior nível de alerta da Organização, devido à alta transmissibilidade do vírus de forma comunitária (Opas, 2020). Pouco tempo depois, em 11 de março de 2020, a COVID-19 foi caracterizada pela OMS como uma pandemia global (ONU Brasil, 2020).

A garantia da proteção internacional era e continua sendo, também, necessária em decorrência do caráter letal, principalmente, para pessoas pertencentes a determinados grupos e diante da ausência de vacina e de medicamentos apropriados; embora, alguns sintomas da doença sejam considerados leves pela medicina.

4 Artigo 33 - Cada Estado Parte considerará a possibilidade de incorporar em seu ordenamento jurídico interno medidas apropriadas para proporcionar proteção contra todo trato injusto às pessoas que denunciem ante as autoridades competentes, de boa-fé e com motivos razoáveis, quaisquer feitos relacionados com os delitos qualificados de acordo com a presente Convenção. 
Não se pode ignorar também que a propagação do vírus alterou o comportamento da sociedade, o fechamento de fronteiras, ensejou reflexos na economia, restrição do comércio e produziu problemas no sistema de saúde em diversas localidades, com alto número de óbitos (Gama Neto, 2020).

A pandemia impactou o mercado de ações ao redor do mundo, sendo necessária a adoção de medidas para mitigar os efeitos econômicos decorrentes desta situação (Remolina, 2020). A desaceleração considerável da atividade econômica produziu declínio nos valores das commodities, na elevação nos preços de ativos financeiros e trouxe um ambiente desafiador para as economias emergentes (Bacen, 2020).

A Organização Mundial do Comércio (2020), diante do cenário, avaliou um declínio no comércio internacional de 13 a 32\%. A propagação do vírus atingiu diretamente o setor dos transportes e o turismo, ocasionando a perda de milhões de empregos.

Pois bem, a proteção internacional em casos que envolvem a coletividade é essencial porque há reflexos negativos sobre os direitos humanos, em especial a alimentação e a saúde. Segundo a Comissão Econômica para a América Latina e Caribe (CEPAL), projeta-se aumento da pobreza na região latino-americana, com estimativa de aproximadamente 30 milhões de pessoas, podendo chegar a 215.000 .000 milhões de pobres (CEPAL, 2020). Além disso, a pobreza extrema poderá atingir 83 milhões (CEPAL, 2020).

A pandemia gerou a publicação de inúmeros atos normativos ao redor do mundo, e, obrigou uma mudança no comportamento dos governos que tiveram que adotar medidas rápidas com a finalidade de reduzir os efeitos desastrosos de proliferação do vírus causador da doença de COVID-19.

O médico chinês Dr. Li Wenliang ao identificar a gravidade do vírus e, na tentativa de alertar seus colegas e ex-colegas de classe acerca do surto da doença e da proximidade desta, foi vítima de diversas retaliações. O caso foi examinado pelo Supremo Tribunal Popular da China que fez duras críticas à polícia de Wuhan por repreender além do médico, outros sete cidadãos por "espalharem boatos" sobre a doença ainda no final de dezembro de 2019 (Caixin, 2020).

O Tribunal em sua análise considerou que tanto o médico como os demais sete cidadãos não poderiam ter sido repreendido, pois as informações por eles divulgadas não se tratavam de informações falsas (Nikkei Asian Review, 2020). Da mesma maneira, Dr. Li Wenliang como profissional da área, teve contato direto com pacientes infectados, possuía informações precisas e, por isso, soube identificar o risco iminente, e, posteriormente, concreto para a saúde.

Diante desses acontecimentos, constata-se que o médico chinês Dr. Li Wenliang ocupou de fato o papel de whistleblower ou de denunciante de boa-fé ao alertar colegas e ex-colegas de classe acerca da gravidade do vírus SARS-CoV-2 que desencadeou 
a pandemia. À vista disso, reafirma-se que o direito à proteção da pessoa humana, previsto em documentos internacionais de direitos humanos, deveria ter sido assegurado ao médico chinês pela via da cooperação internacional.

\section{CONCLUSÕES}

O artigo propôs a aplicação do instituto do whistleblowing ao caso do médico chinês Dr. Li Wenliang, tendo em vista que se portou como denunciante de boa-fé em relação à pandemia de COVID-19. O médico alertou os companheiros de trabalho sobre o surto da doença e recomendou o uso de equipamentos de segurança a fim de evitarem a contaminação e a disseminação do vírus. Ao invés de receber proteção das autoridades chinesas, foi investigado pela polícia sob acusação de "espalhar boatos" relacionados à pandemia.

Os documentos internacionais reconhecem os direitos humanos e fundamentais do ser humano. Portanto, o médico chinês era detentor de personalidade internacional, ficando ultrapassadas as teorias que colocavam indivíduos como simples objeto. A concretização e a multiplicação de normas internacionais sobre as liberdades fundamentais consagram os indivíduos como verdadeiros sujeitos de direito, com atuação própria e autônoma perante diferentes instituições internacionais.

No caso do médico, era legítima a exigência dos direitos humanos como forma de barrar as violações dos seus direitos fundamentais, compromisso de aspiração moral cuja validade jurídica e política na esfera internacional dependem da cooperação de cada Estado na garantia da proteção do denunciante de boa-fé, conforme previsto pelo instituto do whistleblowing.

Relacionados à democracia, à justiça e à igualdade, os direitos humanos legitimam reivindicações de liberdades e, desta forma, constituem-se em uma ideia política e jurídica de base moral. Portanto, o direito de ter sido protegido pelas autoridades chinesas estava legitimado pelos direitos humanos e respaldado legalmente pelo whistleblowing porque era um denunciante de riscos específicos para a saúde pública.

No contexto internacional, qualquer Estado tem por obrigação legal que reconhecer o direito à proteção, independentemente do sistema político e socioeconômico adotado. O paradoxo do caso do médico chinês é o paradoxo de uma sociedade impotente para superar o plano de um formalismo abstrato da proteção da pessoa humana e, assim, levá-la a uma efetivação concreta nas instituições pela via da cooperação.

Para que a proteção da pessoa humana seja efetivamente garantida na escala da cooperação internacional, será preciso que o paradigma clássico baseado nas sociedades nacionais seja substituído pela sociedade global. A partir dessa ideia, os conceitos clássicos de soberania e de hegemonia, ainda firmemente arraigados na doutrina política e jurídica das nações, deverão ser alterados e novos 
horizontes deverão ser buscados para o desenvolvimento da personalidade humana na esfera internacional.

A internacionalização dos direitos humanos é uma das mais importantes questões da atualidade. E, a despeito da evidente constatação de desrespeito ao direito à proteção do médico chinês, é verdadeiro que os ideais de universalidade dos direitos humanos defendidos pela Carta das Nações Unidas e manifestados com a Declaração Universal dos Direitos do Homem estão adquirindo uma maior consistência.

Mas é preciso acentuar que se as violações continuam a existir, o problema não está na inexistência de Tratados e de Convenções, senão na necessidade de funcionar mecanismos internacionais de cooperação, os quais ajudariam a dar consistência cada vez mais específica aos direitos gerais e vagos contidos na Declaração Universal.

Enfim, o artigo reafirma que o desafio atual dos direitos humanos não reside em sua fundamentação, mas, sim, em sua concreta proteção. No âmbito penal, visando a garantia dos direitos humanos, entendemos que o Tribunal Penal Internacional TPI-, para além de punir indivíduos pela prática dos crimes mais graves, deveria no futuro ampliar e melhorar a cooperação internacional, levando os países a investigarem e julgarem as violações contra a espécie humana de forma colaborativa em caso de falha dos sistemas nacionais, para garantir que a justiça prevaleça sobre a impunidade.

\section{REFERÊNCIAS}

Assembleia Geral da ONU. (1948). Declaração Universal dos Direitos Humanos. https://www.ohchr.org/EN/ UDHR/Documents/UDHR_Translations/por.pdf

Banco Central do Brasil, Bacen. (2020). Relatório de Inflação (n. 22, n. 1; 85 p.). https://www.bcb.gov.br/ content/ri/relatorioinflacao/202003/ri202003p.pdf

Beltrame, P. A. Sahione, Y. (2019, abril) "Informante do bem" ou whistleblower: críticas e necessários ajustes ao projeto. IBCCRIM - Instituto Brasileiro de Ciências Criminais. https://bit.ly/37eYp2n

Brasil. Decreto no 5687 de 31 de janeiro de 2006. http:/www.planalto.gov.br/ccivil_03/_ato2004-2006/2006/ decreto/d5687.htm

Brasil. Lei n. 13.608, de 10 de janeiro de 2018. http://www.planalto.gov.br/ccivil_03/_Ato2015-2018/2018/ Lei/L13608.htm

Brasil. Lei no 13.946, de 24 de dezembro de 2019. http://www.planalto.gov.br/ccivil_03/_ato2019-2022/2019/ lei/L13964.htm

Caixin global. (2020, 06 de febrero). Whistleblower Li Wenliang: There Should Be More Than One Voice In A Healthy Society. https://www.caixinglobal.com/2020-02-06/after-being-punished-by-local-policecoronavirus-whistleblower-vindicated-by-top-court-101509986.html

Cepal. (2020, 12 de mayo). El desafio social em tempos del COVID -19 (n 3). https://repositorio.cepal.org/ bitstream/handle/11362/45527/5/S2000325_es.pdf

Cepal. (2020, 16 de junio). Cómo evitar que la crisis del COVID-19 se transforme em uma crisis alimentaria. https://repositorio.cepal.org/bitstream/handle/11362/45702/4/S2000393_es.pdf 
Cnn. (2020, 12 de junio). Widow of Wuhan whistleblower doctor Li Wenliang gives birth to their son. https:// cnn.it/37fl6T 1

Estratégia Nacional de Combate à Corrupção e à Lavagem de Dinheiro, Enccla. (2016). O que é o whistleblower. http://enccla.camara.leg.br/noticias/o-que-e-o-whistleblower

Gama Neto, R. B. (2020). Impactos da covid-19 sobre a economia mundial. Boletim de Conjuntura (BOCA), 2(5), 113-127. https://doi.org/10.5281/zenodo.3786698

Greenwald, G., MacAskill, E., \& Poitras, L. (2013, junho 11). Edward Snowden: The whistleblower behind the NSA surveillance revelations. The Guardian. https://www.theguardian.com/world/2013/jun/09/ edward-snowden-nsa-whistleblower-surveillance

Maslen, C. (2018). Whistleblower Reward Programmes. Transparency International. https://knowledgehub. transparency.org/assets/uploads/helpdesk/Whistleblower-Reward-Programmes-2018.pdf

Mazzuoli, V. de O. (2015). Curso de direito internacional público (9. Ed). Editora Revista dos Tribunais.

Miguel, R. de. (2019, 13 de junio). Reino Unido assina ordem de extradição de Julian Assange para os EUA. El País. https://brasil.elpais.com/brasil/2019/06/13/internacional/1560417837_663803.html

Ministério Público do Estado do Paraná, MPPR. ([s.d.]) Marco Normativo Interno Institutos afins ao whistleblower Identificação de possíveis pontos de convergência e divergência da normativa brasileira Recomendações internacionais. https://criminal.mppr.mp.br/arquivos/File/04_Marco_normativo_interno.pdf

Mota Jr. J. F. da. (2012). A proteção do servidor público denunciante (whistleblower). Um enfoque na recente tutela jurídica brasileira. Derecho y Cambio Social. Lima, 9(30), 22.

Nie, J-B., Elliott C. (2020). Humiliating Whistle-Blowers: Li Wenliang, the Response to Covid-19, and the Call for a Decent Society. Journal of Bioethical Inquiry. 17(4), 543-547. https://doi.org/10.1007/ s1 1673-020-09990-x

Nikkei Asian Review. (2020, 05 de fevereiro). Rebuked coronavirus whistleblower vindicated by top Chinese court. https://asia.nikkei.com/Spotlight/Caixin/Rebuked-coronavirus-whistleblowervindicated-by-top-Chinese-court

Oliveira, J. M. F. (2015). A urgência de uma legislação whisteblowing no Brasil. Brasilia: Núcleo de Estudos e Pesquisa/CONLEG/Senado. https://www12.senado.leg.br/publicacoes/estudos-legislativos/tiposde-estudos/textos-para-discussao/td175/view

ONU Brasil. (2020, 11 de marzo). Organização Mundial da Saúde classifica novo coronavírus como pandemia. https://bit.ly/2TORU3c

Opas. (2020, 31 de agosto). Folha informativa covid-19 - Escritório da opas e da oms no brasil. http://www.paho.org/pt/covid19

Organização Mundial do Comércio, Omc. (2020, 08 de abril) Trade set to plunge as COVID-19 pandemic upends global economy. https://www.wto.org/english/news_e/pres20_e/pr855_e.htm

Paiva, D. T. Pegoraro. M. M. do L. A. Whistleblower: efetiva técnica de prevenção ou incentivo aos caçadores de recompensas?. Em Lamy, Eduardo (org.) (2018). Compliance: aspectos polêmicos e atuais, pp. 53-60. Letramento: Casa do Direito.

Petersen, E., Hui, D., Hamer, D. H., Blumberg, L., Madoff, L. C., Pollack, M., Lee, S. S., McLellan, S., Memish, Z., Praharaj, I., Wasserman, S., Ntoumi, F., Azhar, E. I., Mchugh, T. D., Kock, R., Ippolito, G., Zumla, A., E Koopmans, M. (2020). Li Wenliang, a face to the frontline healthcare worker. 
The first doctor to notify the emergence of the SARS-CoV-2, (COVID-19), outbreak. International journal of infectious diseases: IJID : official publication of the International Society for Infectious Diseases, 93, 205-207. https://doi.org/10.1016/j.ijid.2020.02.052

Ramos, J. (2018). A proteção de denunciantes em Portugual: Estado da Arte (p. 45). Transparency International Portugal. https://transparencia.pt/wp-content/uploads/2018/07/TI-PT_ProtecaoDenunciantesPor tugal_2018-last-version_24_07_2018_VF.pdf

Remolina, N. (2020). Respuestas de supervisores y reguladores financieros al covid-19(Financial regulators' responses to covid/19) (SSRN Scholarly Paper ID 3554557). Social Science Research Network. https://papers.ssrn. com/abstract $=3554557$

Rosa, A. M. da. (2018). Compliance e delação como mecanismos complementares do amor ao censor. Em E. Lamy (org.) Compliance: aspectos polêmicos e atuais (pp. 19-32). Letramento: Casa do Direito.

Superior Tribunal de Justiça, STJ. (2017, 28 de noviembre). Habeas Corpus n 413.160 - PE. https://ww2. stj.jus.br/processo/revista/inteiroteor/?num_registro $=201702092850 \varepsilon d t \_p u b l i c a c a o=28 / 11 / 2017$

The Guardian. (2020, 20 de marzo). Chinese inquiry exonerates coronavirus whistleblower doctor. http://www. theguardian.com/world/2020/mar/20/chinese-inquiry-exonerates-coronavirus-whistleblowerdoctor-li-wenliang

Triviño, J. L. P. (2018). Whistleblowing. Eunomía. Revista en Cultura de la Legalid, (14), 285-298. https:// doi.org/10.20318/eunomia.2018.4170

Zhou, F., Yu, T., Du, R., Fan, G., Liu, Y., Liu, Z., Xiang, J., Wang, Y., Song, B., Gu, X., Guan, L., Wei, Y.,

Li, H., Wu, X., Xu, J., Tu, S., Zhang, Y., Chen, H., \& Cao, B. (2020). Clinical course and risk factors for mortality of adult inpatients with COVID-19 in Wuhan, China: A retrospective cohort study. The Lancet, 395(10229), 1054-1062. https://doi.org/10.1016/S0140-6736(20)30566-3 